OFFICIAL ARPA-INTERNET PROTOCOLS

STATUS OF THIS MEMO

This memo is an official status report on the protocols used in the ARPA-Internet community. Distribution of this memo is unlimited.

\title{
INTRODUCTION
}

This RFC identifies the documents specifying the official protocols used in the Internet. Comments indicate any revisions or changes planned.

To first order, the official protocols are those in the "Internet Protocol Transition Workbook" (IPTW) dated March 1982. There are several protocols in use that are not in the IPTW. A few of the protocols in the IPTW have been revised. Notably, the mail protocols have been revised and issued as a volume titled "Internet Mail Protocols" dated November 1982. Telnet and the most useful Telnet options have been revised and issued as a volume titled "Internet Telnet Protocol and Options" (ITP) dated June 1983. The File Transfer Protocol has been revised most recently as RFC 959 which is not yet included in any collection. Some protocols have not been revised for many years, these are found in the old "ARPANET Protocol Handbook" (APH) dated January 1978. There is also a volume of protocol related information called the "Internet Protocol Implementers Guide" (IPIG) dated August 1982.

This document is organized as a sketchy outline. The entries are protocols (e.g., Transmission Control Protocol). In each entry there are notes on status, specification, comments, other references, dependencies, and contact.

The STATUS is one of: required, recommended, elective, or experimental.

The SPECIFICATION identifies the protocol defining documents.

The COMMENTS describe any differences from the specification or problems with the protocol.

The OTHER REFERENCES identify documents that comment on or expand on the protocol. 
The DEPENDENCIES indicate what other protocols are called upon by this protocol.

The CONTACT indicates a person who can answer questions about the protocol.

In particular, the status may be:

required

- all hosts must implement the required protocol, recommended

- all hosts are encouraged to implement the recommended protocol,

elective

- hosts may implement or not the elective protocol,

experimental

- hosts should not implement the experimental protocol unless they are participating in the experiment and have coordinated their use of this protocol with the contact person, and

none

- this is not a protocol.

For further information about protocols in general, please contact:

Joyce Reynolds

USC - Information Sciences Institute

4676 Admiralty Way

Marina del Rey, California 90292-6695

Phone: (213) 822-1511

ARPA mail: JKREYNOLDSQUSC-ISIB.ARPA 
OVERVIEW

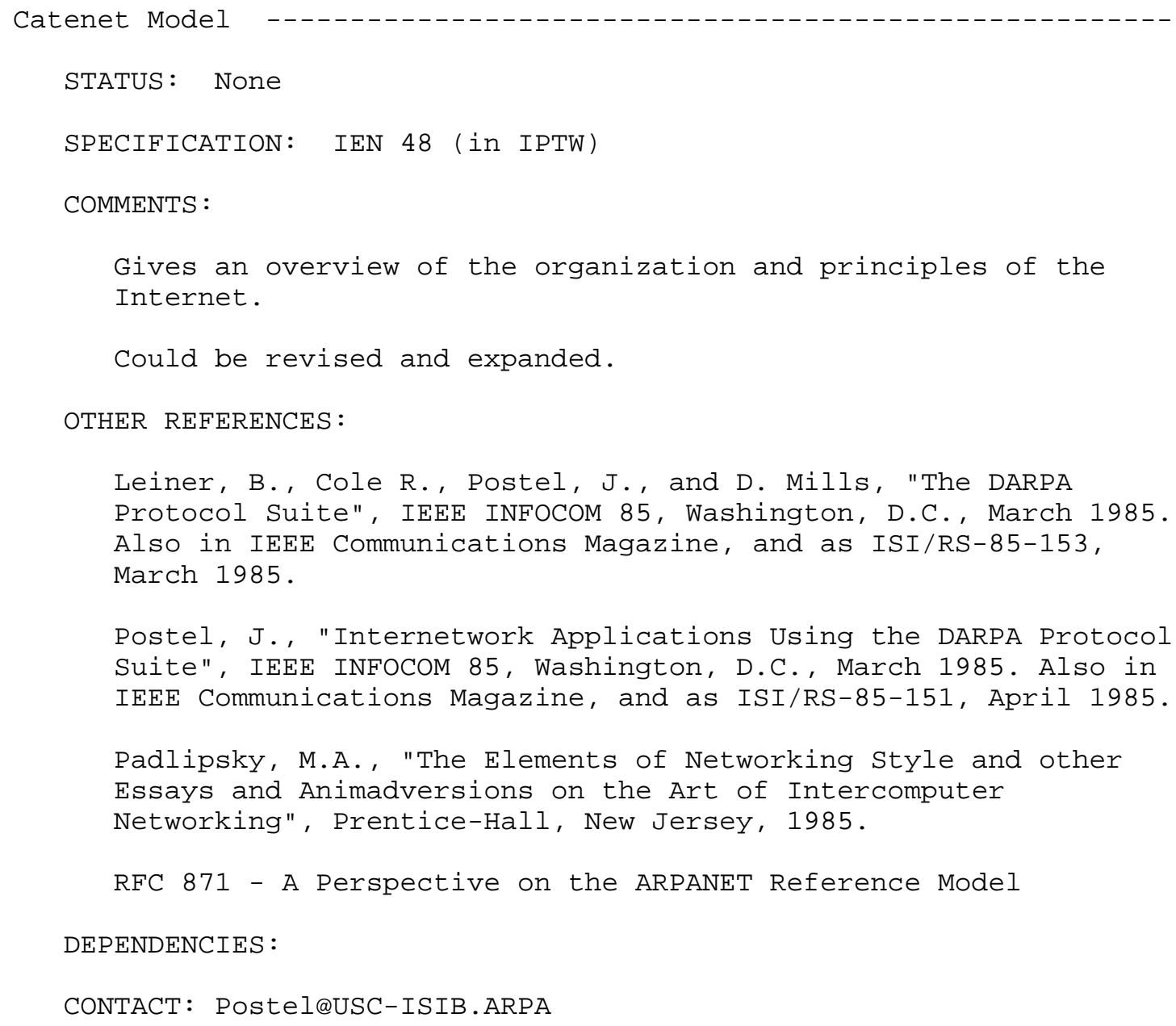


NETWORK LEVEL

Internet Protocol

STATUS: Required

SPECIFICATION: RFC 791 (in IPTW)

COMMENTS :

This is the universal protocol of the Internet. This datagram protocol provides the universal addressing of hosts in the Internet.

A few minor problems have been noted in this document.

The most serious is a bit of confusion in the route options. The route options have a pointer that indicates which octet of the route is the next to be used. The confusion is between the phrases "the pointer is relative to this option" and "the smallest legal value for the pointer is 4". If you are confused, forget about the relative part, the pointer begins at 4 .

Another important point is the alternate reassembly procedure suggested in RFC 815.

Some changes are in the works for the security option.

Note that ICMP is defined to be an integral part of IP. You have not completed an implementation of IP if it does not include ICMP.

OTHER REFERENCES:

RFC 815 (in IPIG) - IP Datagram Reassembly Algorithms

RFC 814 (in IPIG) - Names, Addresses, Ports, and Routes

RFC 816 (in IPIG) - Fault Isolation and Recovery

RFC 817 (in IPIG) - Modularity and Efficiency in Protocol

Implementation

MIL-STD-1777 - Military Standard Internet Protocol

RFC 963 - Some Problems with the Specification of the Military Standard Internet Protocol 
DEPENDENCIES :

CONTACT: Postel@USC-ISIB.ARPA

Internet Control Message Protocol

( ICMP)

STATUS: Required

SPECIFICATION: RFC 792 (in IPTW)

COMMENTS :

The control messages and error reports that go with the Internet Protocol.

A few minor errors in the document have been noted. Suggestions have been made for additional types of redirect message and additional destination unreachable messages.

A proposal for two additional ICMP message types is made in RFC 950 "Internet Subnets", Address Mask Request ( $A 1=17)$, and Address Mask Reply $(\mathrm{A} 2=18)$. The details of these ICMP types are subject to change. Use of these ICMP types is experimental.

Note that ICMP is defined to be an integral part of IP. You have not completed an implementation of IP if it does not include ICMP.

OTHER REFERENCES: RFC 950

DEPENDENCIES: Internet Protocol

CONTACT: Postel@USC-ISIB.ARPA 
HOST LEVEL

User Datagram Protocol --------------------------------------- (UDP)

STATUS: Recommended

SPECIFICATION: RFC 768 (in IPTW)

COMMENTS :

Provides a datagram service to applications. Adds port addressing to the IP services.

The only change noted for the UDP specification is a minor clarification that if in computing the checksum a padding octet is used for the computation it is not transmitted or counted in the length.

OTHER REFERENCES :

DEPENDENCIES: Internet Protocol

CONTACT: Postel@USC-ISIB.ARPA

Transmission Control Protocol

STATUS: Recommended

SPECIFICATION: RFC 793 (in IPTW)

COMMENTS :

Provides reliable end-to-end data stream service.

Many comments and corrections have been received for the TCP specification document. These are primarily document bugs rather than protocol bugs.

Event Processing Section: There are many minor corrections and clarifications needed in this section.

Push: There are still some phrases in the document that give a "record mark" flavor to the push. These should be further clarified. The push is not a record mark.

Urgent: Page 17 is wrong. The urgent pointer points to the last octet of urgent data (not to the first octet of non-urgent data). 
Listening Servers: Several comments have been received on difficulties with contacting listening servers. There should be some discussion of implementation issues for servers, and some notes on alternative models of system and process organization for servers.

Maximum Segment Size: The maximum segment size option should be generalized and clarified. It can be used to either increase or decrease the maximum segment size from the default. The TCP Maximum Segment Size is the IP Maximum Datagram Size minus forty. The default IP Maximum Datagram Size is 576. The default TCP Maximum Segment Size is 536. For further discussion, see RFC 879 .

Idle Connections: There have been questions about automatically closing idle connections. Idle connections are ok, and should not be closed. There are several cases where idle connections arise, for example, in Telnet when a user is thinking for a long time following a message from the server computer before his next input. There is no TCP "probe" mechanism, and none is needed.

Queued Receive Data on Closing: There are several points where it is not clear from the description what to do about data received by the TCP but not yet passed to the user, particularly when the connection is being closed. In general, the data is to be kept to give to the user if he does a RECV call.

Out of Order Segments: The description says that segments that arrive out of order, that is, are not exactly the next segment to be processed, may be kept on hand. It should also point out that there is a very large performance penalty for not doing so.

User Time Out: This is the time out started on an open or send call. If this user time out occurs the user should be notified, but the connection should not be closed or the TCB deleted. The user should explicitly ABORT the connection if he wants to give up.

OTHER REFERENCES:

RFC 813 (in IPIG) - Window and Acknowledgement strategy in TCP

RFC 814 (in IPIG) - Names, Addresses, Ports, and Routes

RFC 816 (in IPIG) - Fault Isolation and Recovery 


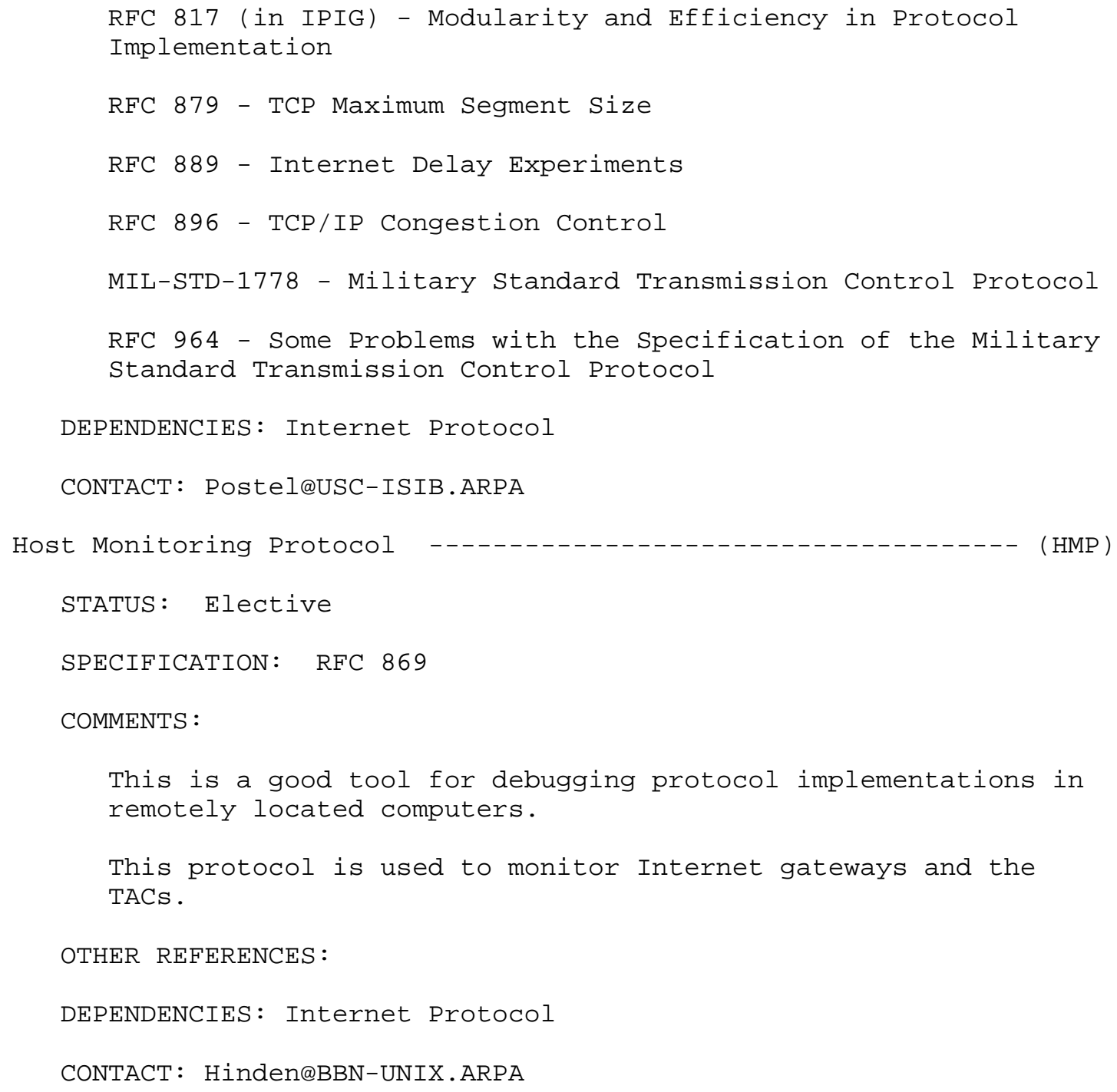




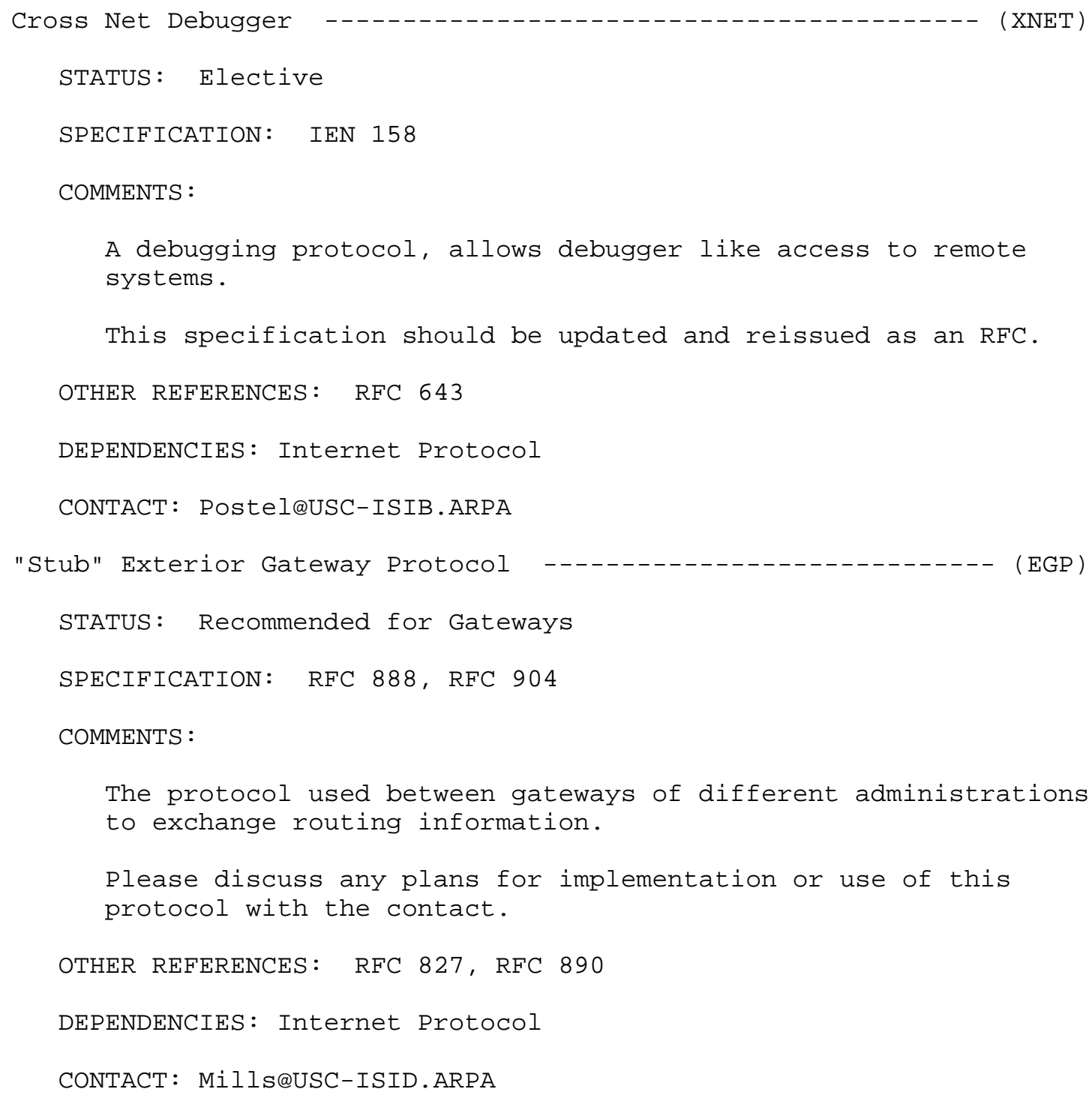




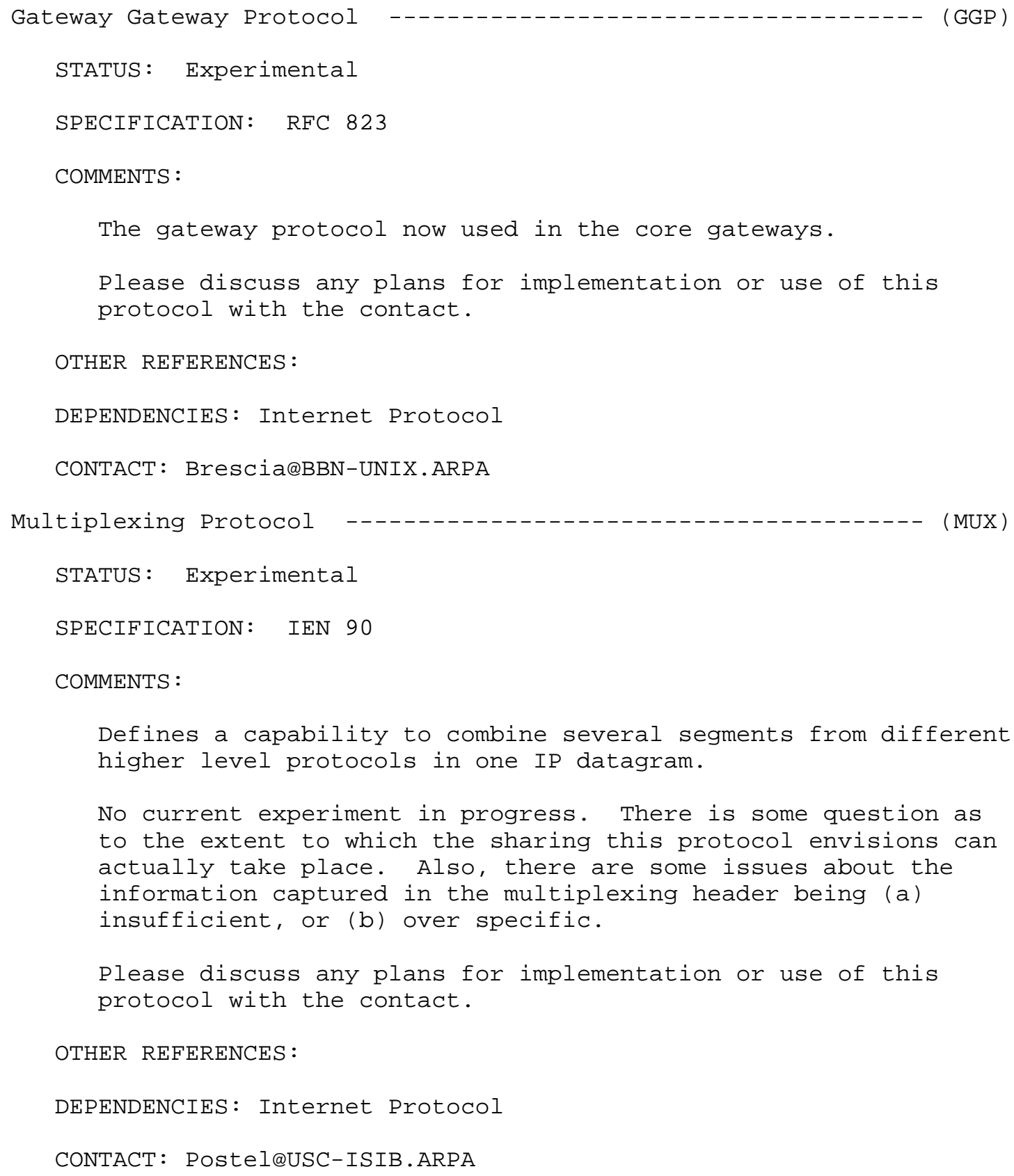




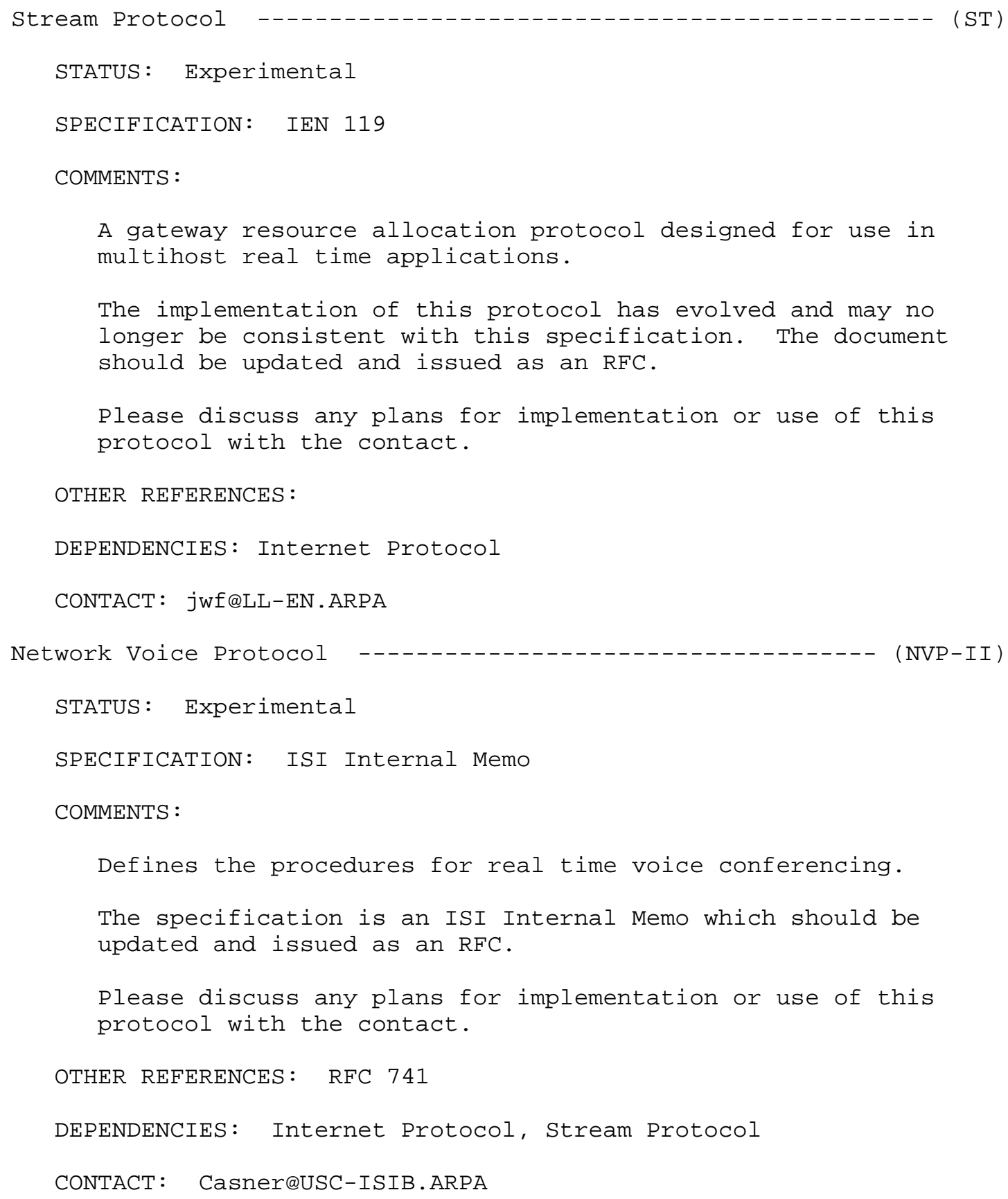




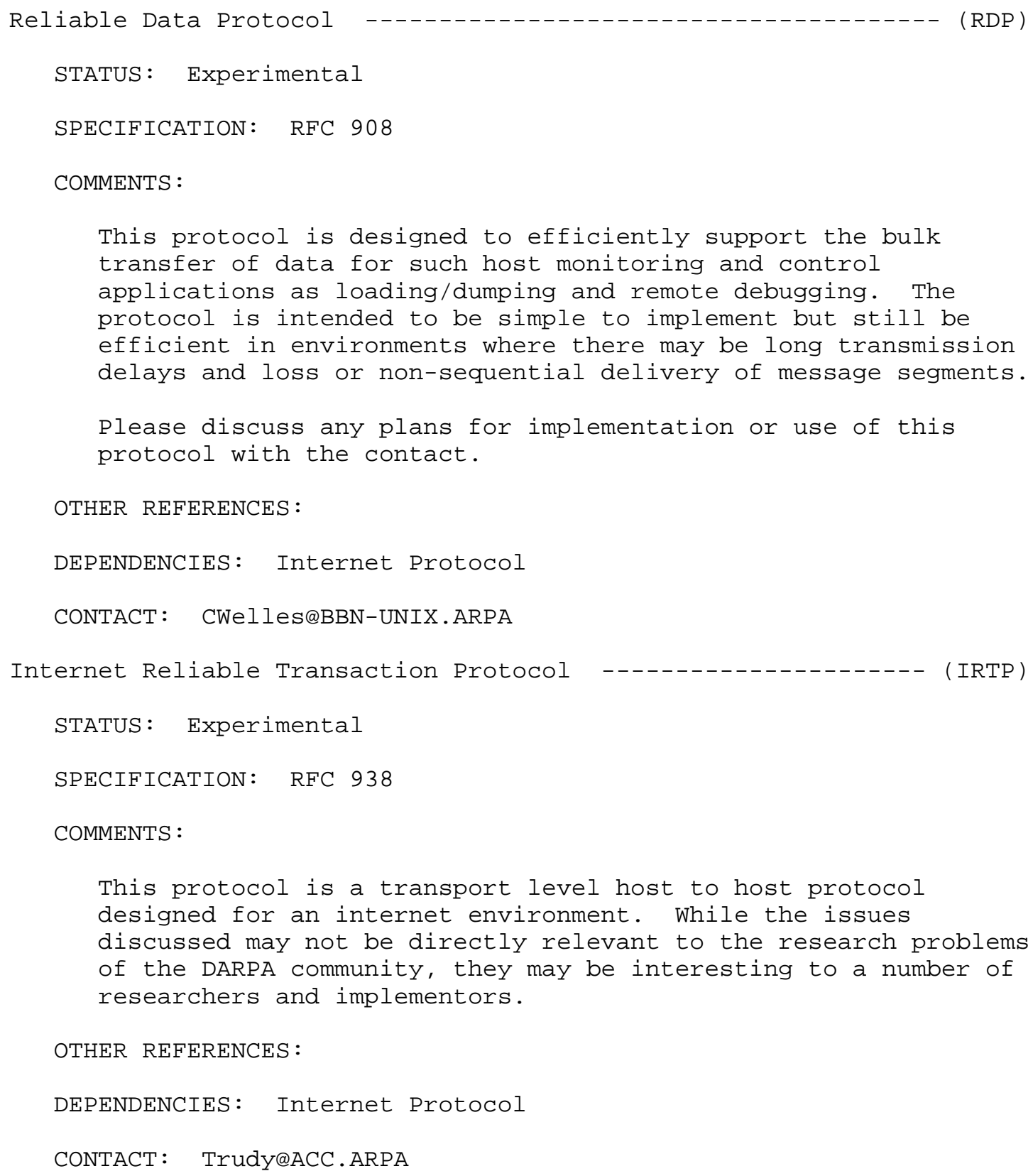


APPLICATION LEVEL

Telnet Protocol

(TELNET)

STATUS: Recommended

SPECIFICATION: RFC 854 (in "Internet Telnet Protocol and Options")

COMMENTS :

The protocol for remote terminal access.

This has been revised since the IPTW. RFC 764 in IPTW is now obsolete.

OTHER REFERENCES :

MIL-STD-1782 - Telnet Protocol

DEPENDENCIES: Transmission Control Protocol

CONTACT: Postel@USC-ISIB.ARPA 
Telnet Options ---------------------------------- (TELNET-OPTIONS) STATUS: Elective

SPECIFICATION: General description of options: RFC 855 (in "Internet Telnet Protocol and Options")

$\begin{array}{cl}\text { Number } & \text { Name } \\ 0 & \text { Binary Transmission } \\ 1 & \text { Echo } \\ 2 & \text { Reconnection } \\ 3 & \text { Suppress Go Ahead } \\ 4 & \text { Approx Message Size Negotiation } \\ 5 & \text { Status } \\ 6 & \text { Timing Mark } \\ 7 & \text { Remote Controlled Trans and Echo } \\ 8 & \text { Output Line Width } \\ 9 & \text { Output Page Size } \\ 10 & \text { Output Carriage-Return Disposition } \\ 11 & \text { Output Horizontal Tabstops } \\ 12 & \text { Output Horizontal Tab Disposition } \\ 13 & \text { Output Formfeed Disposition } \\ 14 & \text { Output Vertical Tabstops } \\ 15 & \text { Output Vertical Tab Disposition } \\ 16 & \text { Output Linefeed Disposition } \\ 17 & \text { Extended AScII } \\ 18 & \text { Logout } \\ 19 & \text { Byte Macro } \\ 20 & \text { Data Entry Terminal } \\ 21 & \text { SUPDUP } \\ 22 & \text { SUPDUP Output } \\ 23 & \text { Send Location } \\ 24 & \text { Terminal Type } \\ 25 & \text { End of Record } \\ 26 & \text { TACACS User Identification } \\ 27 & \text { Output Marking } \\ 28 & \text { Terminal Location Number } \\ 255 & \text { Extended-Options-List } \\ & \end{array}$

\begin{tabular}{|c|c|c|c|c|}
\hline $\mathrm{FC}$ & NIC & ITP & $\mathrm{APH}$ & USE \\
\hline-- & ----- & --- & --- & --- \\
\hline 56 & ----- & yes & obs & yes \\
\hline 57 & ----- & yes & obs & yes \\
\hline & 15391 & no & yes & no \\
\hline 58 & ----- & yes & obs & es \\
\hline & 15393 & no & yes & no \\
\hline 59 & ----- & yes & obs & yes \\
\hline 60 & ----- & yes & obs & yes \\
\hline 26 & 39237 & no & yes & no \\
\hline . & 20196 & no & yes & no \\
\hline & 20197 & no & yes & no \\
\hline 652 & 31155 & no & yes & no \\
\hline 653 & 31156 & no & yes & no \\
\hline 654 & 31157 & no & yes & no \\
\hline 55 & 31158 & no & yes & no \\
\hline 656 & 31159 & no & yes & no \\
\hline 657 & 31160 & no & yes & no \\
\hline 658 & 31161 & no & yes & no \\
\hline 698 & 32964 & no & yes & no \\
\hline 727 & 40025 & no & yes & no \\
\hline 735 & 42083 & no & yes & no \\
\hline 732 & 41762 & no & yes & no \\
\hline 736 & 42213 & no & yes & no \\
\hline 749 & 45449 & no & no & no \\
\hline 779 & ----- & no & no & no \\
\hline 930 & ----- & no & no & no \\
\hline 885 & ----- & no & no & no \\
\hline 927 & -- & no & no & no \\
\hline 933 & ----- & no & no & no \\
\hline 946 & ----- & no & no & no \\
\hline 861 & ----- & yes & obs & yes \\
\hline
\end{tabular}

The ITP column indicates if the specification is included in the Internet Telnet Protocol and Options. The APH column indicates if the specification is included in the ARPANET Protocol Handbook. The USE column of the table above indicates which options are in general use. 
COMMENTS :

The Binary Transmission, Echo, Suppress Go Ahead, Status, Timing Mark, and Extended Options List options have been recently updated and reissued. These are the most frequently implemented options.

The remaining options should be reviewed and the useful ones should be revised and reissued. The others should be eliminated.

The following are recommended: Binary Transmission, Echo, Suppress Go Ahead, Status, Timing Mark, and Extended Options List.

OTHER REFERENCES :

DEPENDENCIES: Telnet

CONTACT: Postel@USC-ISIB.ARPA

File Transfer Protocol $(\mathrm{FTP})$

\section{STATUS: Recommended}

SPECIFICATION: RFC 959

\section{COMMENTS :}

The protocol for moving files between Internet hosts. Provides for access control and negotiation of file parameters.

The following new optional commands are included in this edition of the specification: Change to Parent Directory (CDUP), Structure Mount (SMNT), store Unique (STOU), Remove Directory (RMD), Make Directory (MKD), Print Directory (PWD), and System (SYST). Note that this specification is compatible with the previous edition (RFC 765).

OTHER REFERENCES:

RFC 678 - Document File Format Standards

MIL-STD-1780 - File Transfer Protocol

DEPENDENCIES: Transmission Control Protocol

CONTACT: Postel@USC-ISIB.ARPA 
STATUS: Elective

SPECIFICATION: RFC 783 (in IPTW)

COMMENTS :

A very simple file moving protocol, no access control is provided.

This is in use in several local networks.

Ambiguities in the interpretation of several of the transfer modes should be clarified, and additional transfer modes could be defined. Additional error codes could be defined to more clearly identify problems.

OTHER REFERENCES:

DEPENDENCIES: User Datagram Protocol

CONTACT: Postel@USC-ISIB.ARPA

Simple File Transfer Protocol

(SFTP)

\section{STATUS: Experimental}

SPECIFICATION: RFC 913

\section{COMMENTS :}

SFTP is a simple file transfer protocol. It fills the need of people wanting a protocol that is more useful than TFTP but easier to implement (and less powerful) than FTP. SFTP supports user access control, file transfers, directory listing, directory changing, file renaming and deleting.

SFTP can be implemented with any reliable 8-bit byte stream oriented protocol, this document describes its TCP specification. SFTP uses only one TCP connection; whereas TFTP implements a connection over UDP, and FTP uses two TCP connections (one using the TELNET protocol).

Please discuss any plans for implementation or use of this protocol with the contact.

OTHER REFERENCES : 


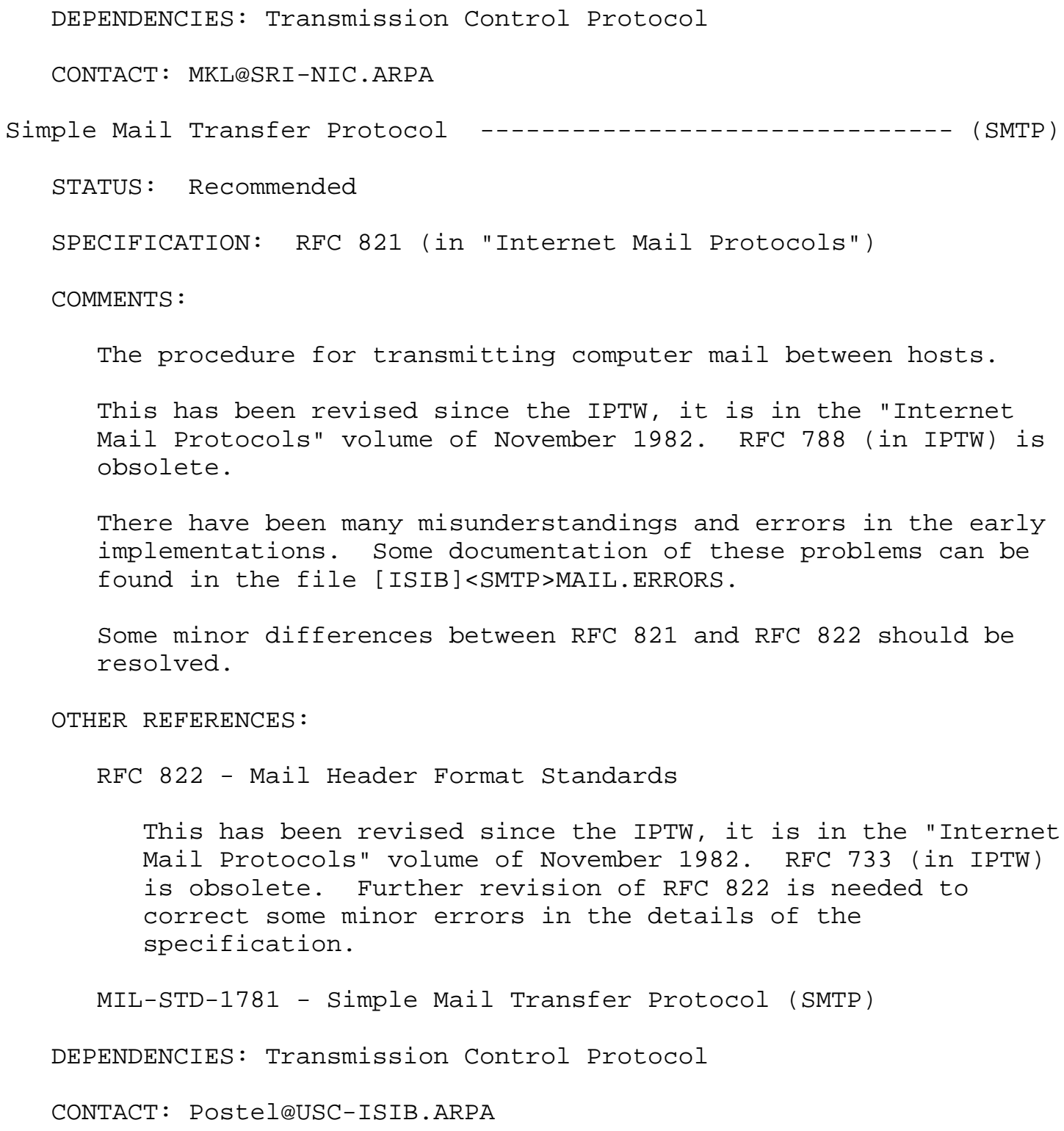




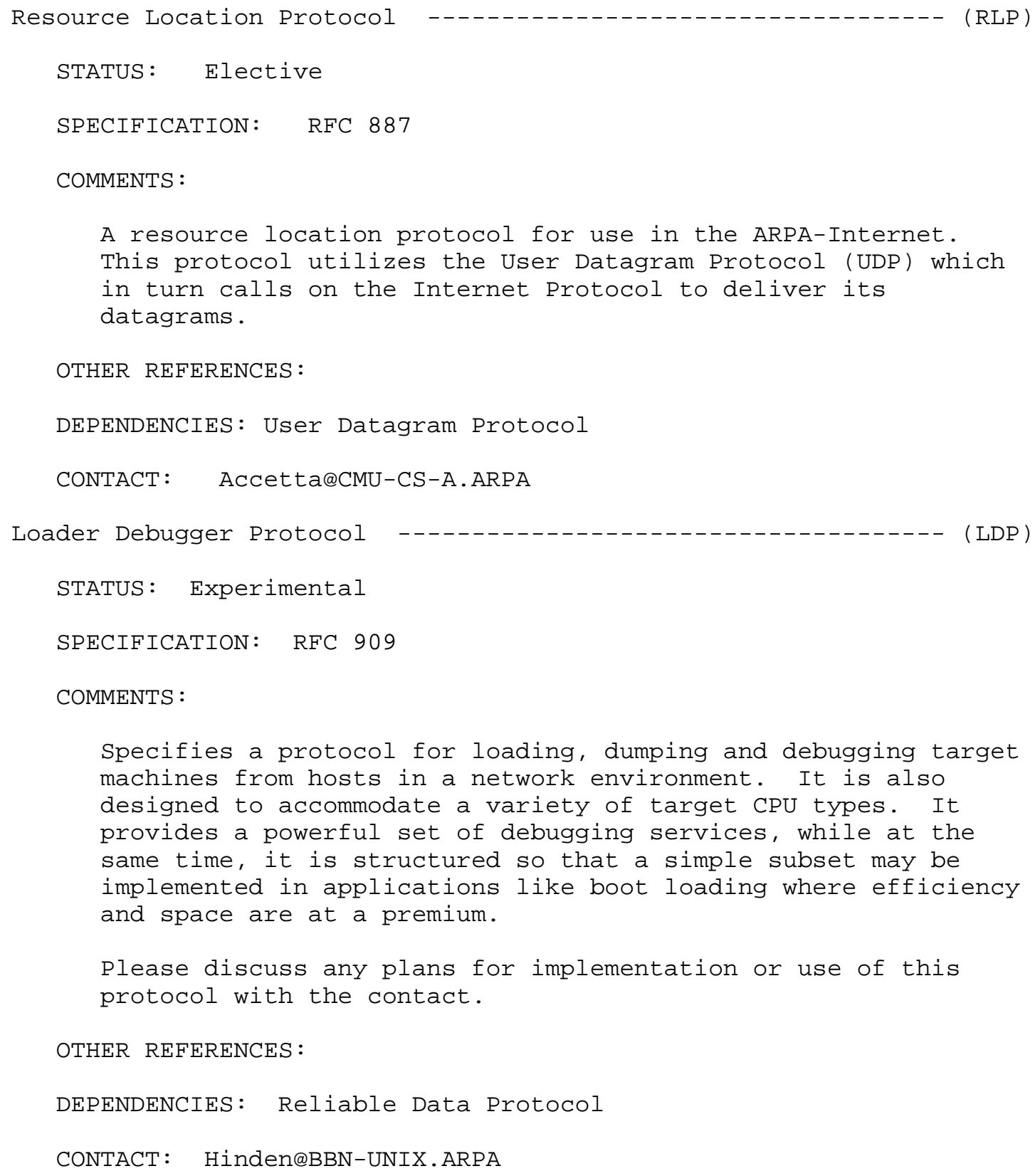




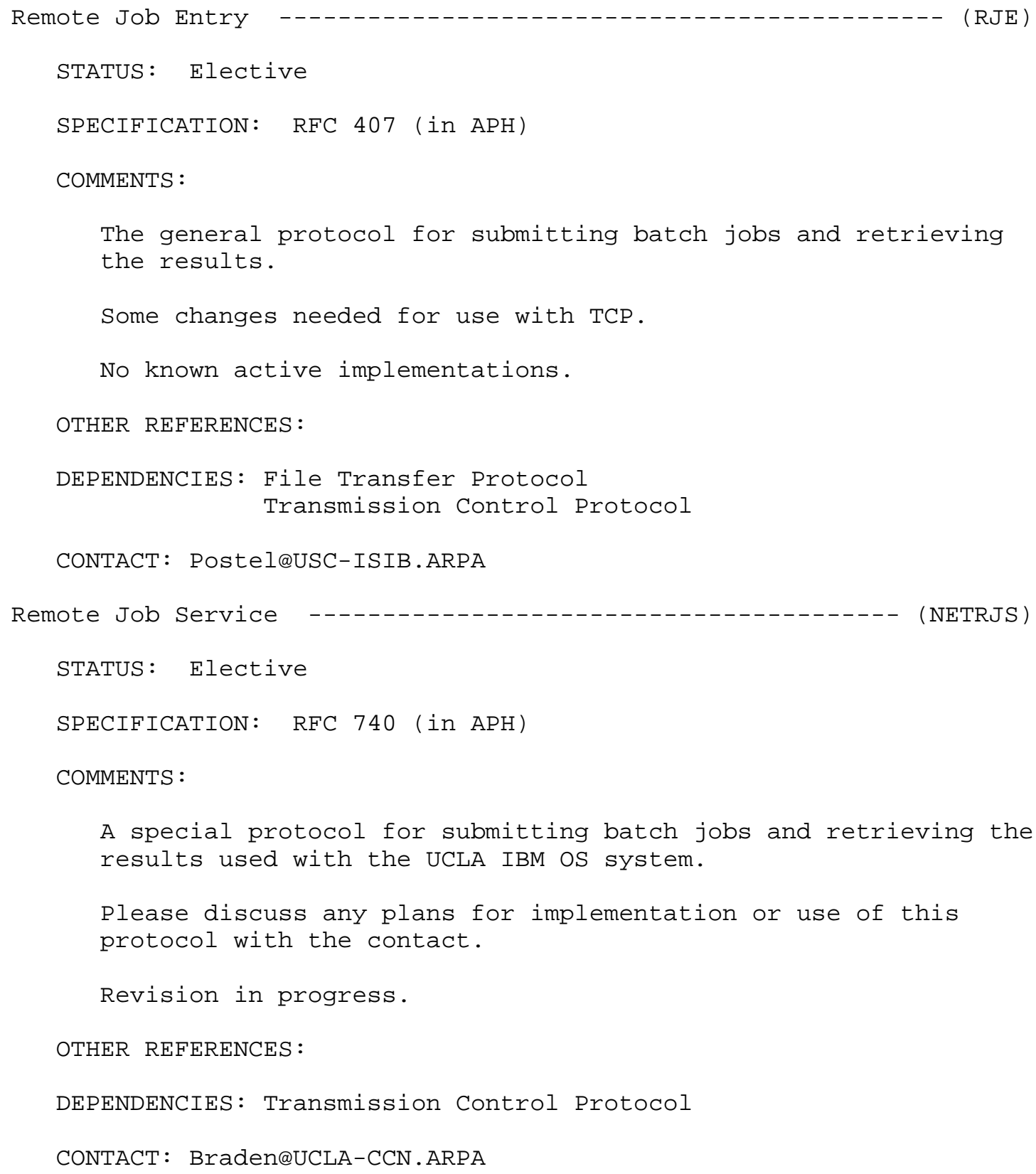




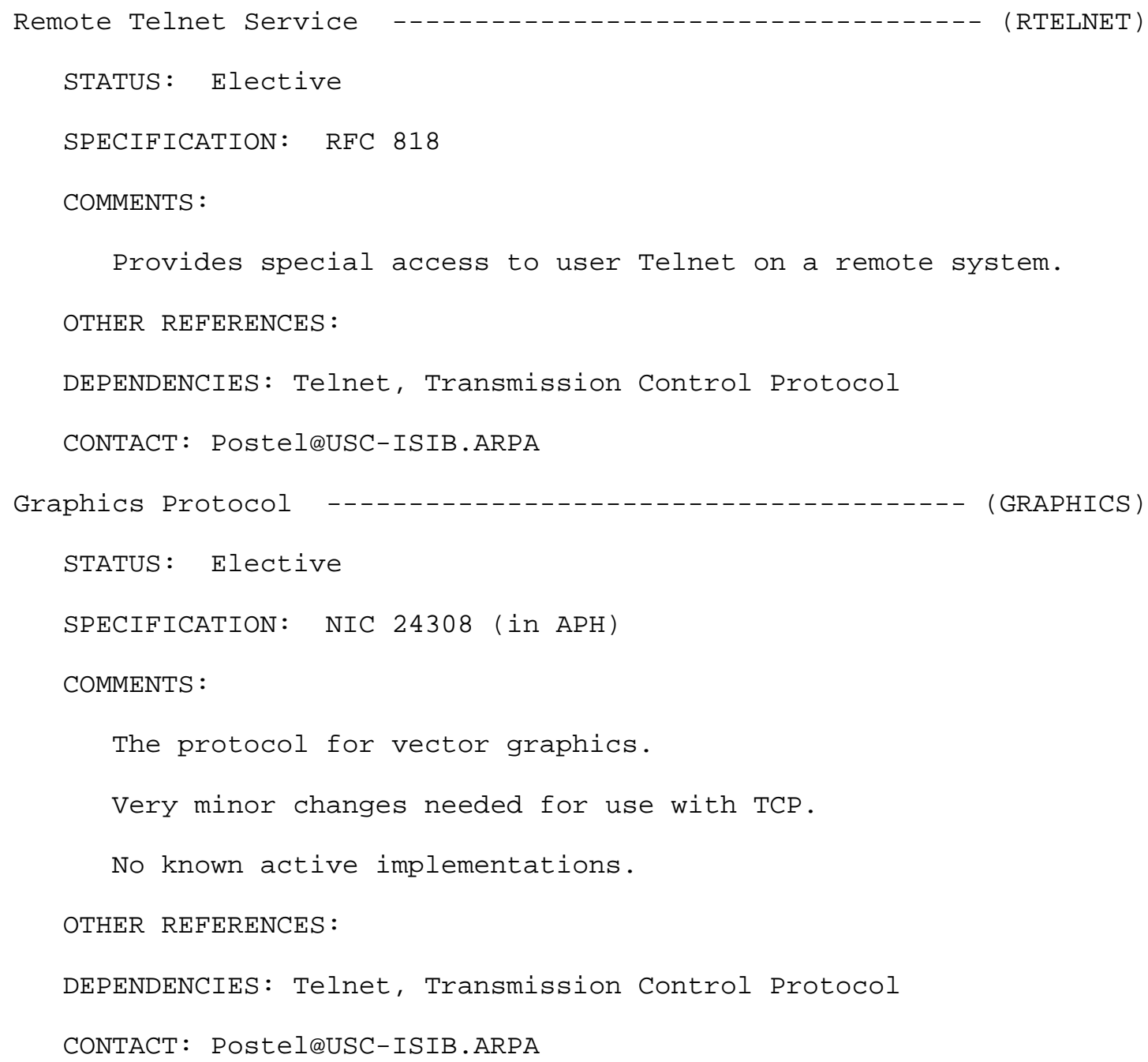




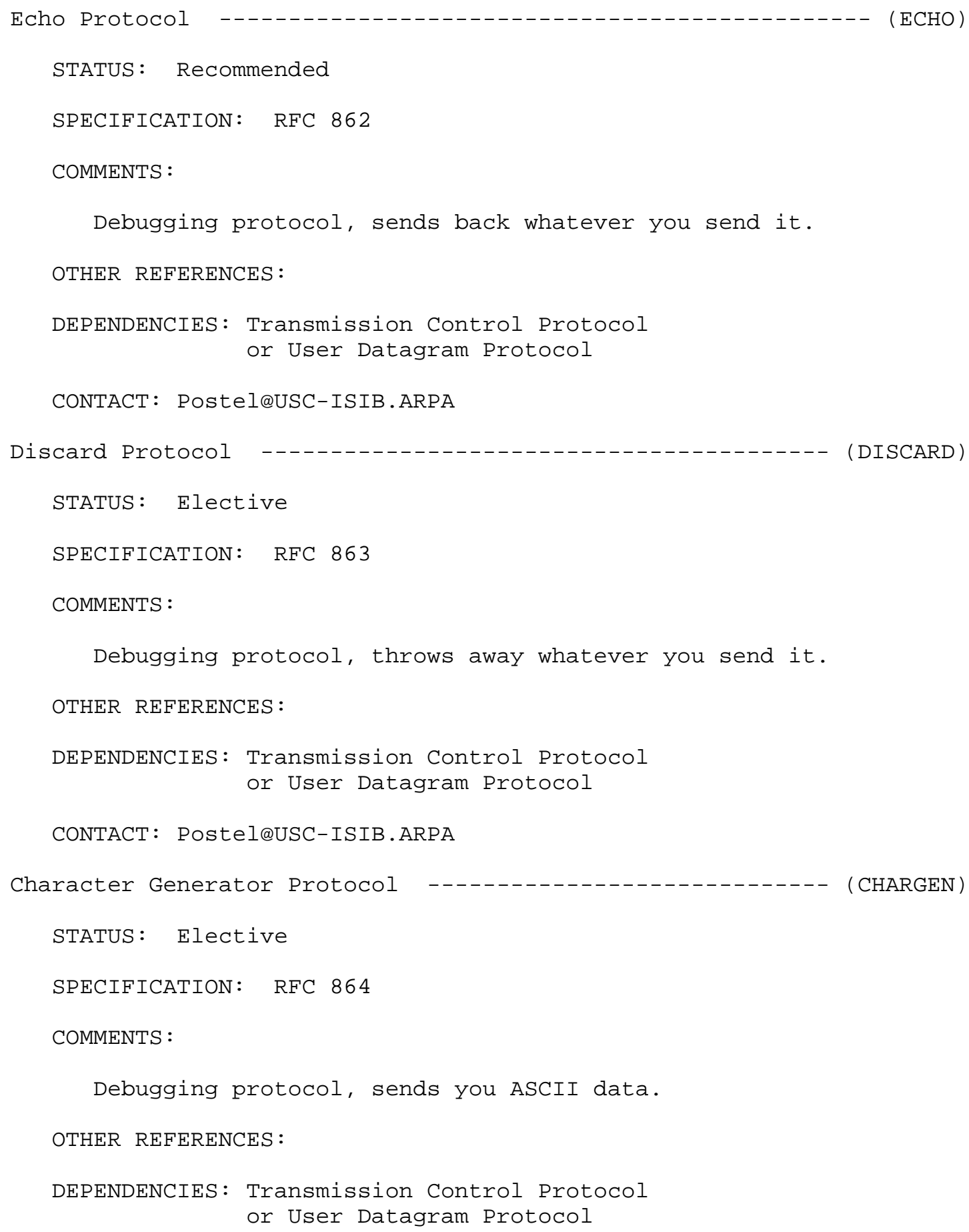


CONTACT: Postel@USC-ISIB.ARPA

Quote of the Day Protocol

(QUOTE)

STATUS: Elective

SPECIFICATION: RFC 865

COMMENTS :

Debugging protocol, sends you a short ASCII message. OTHER REFERENCES :

DEPENDENCIES: Transmission Control Protocol or User Datagram Protocol

CONTACT: Postel@USC-ISIB.ARPA

Active Users Protocol

(USERS)

STATUS: Elective

SPECIFICATION: RFC 866

COMMENTS :

Lists the currently active users.

OTHER REFERENCES:

DEPENDENCIES: Transmission Control Protocol or User Datagram Protocol

CONTACT: Postel@USC-ISIB.ARPA

Finger Protocol

(FINGER)

STATUS: Elective

SPECIFICATION: RFC 742 (in APH)

COMMENTS :

Provides information on the current or most recent activity of a user.

Some extensions have been suggested. 


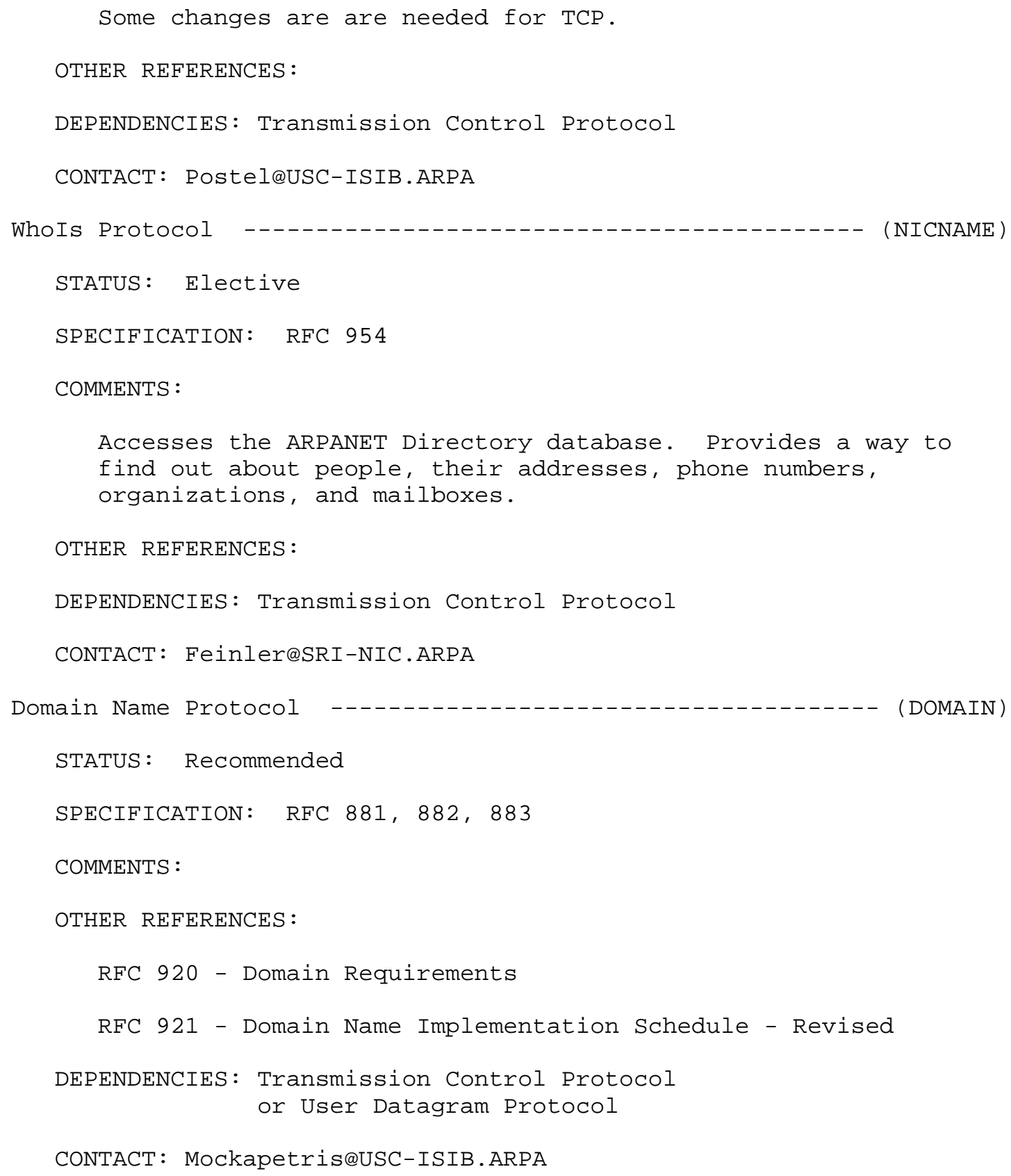




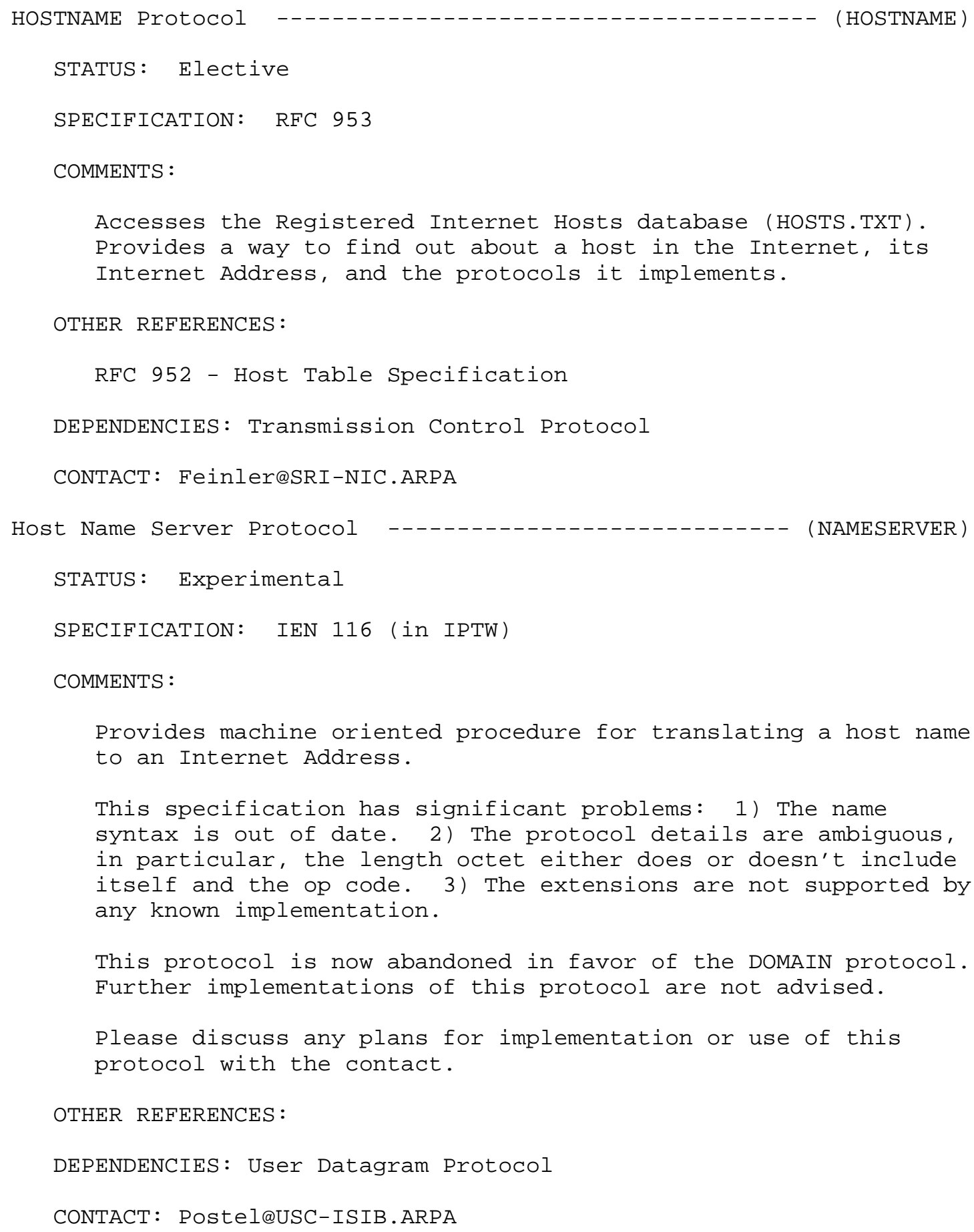




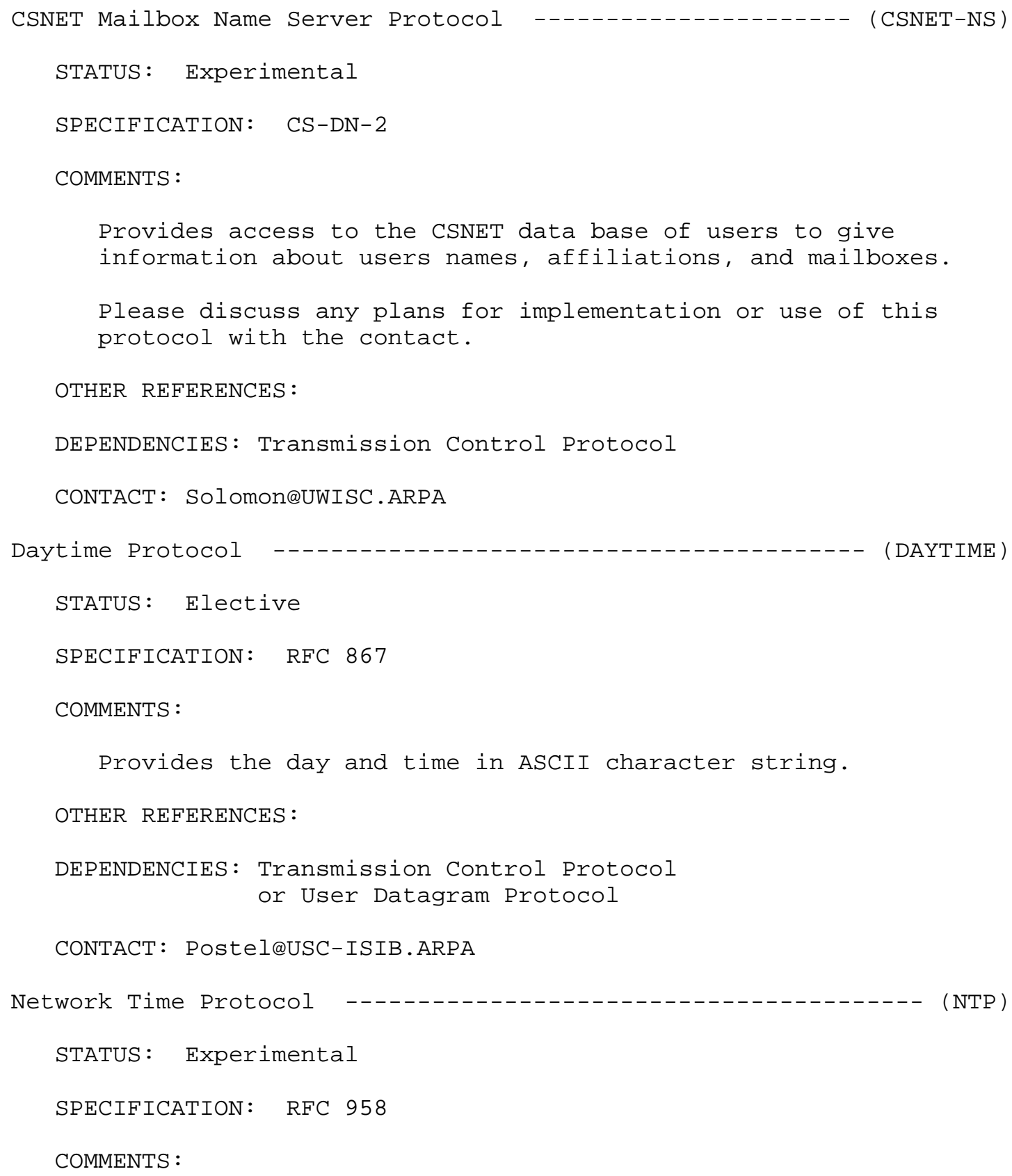




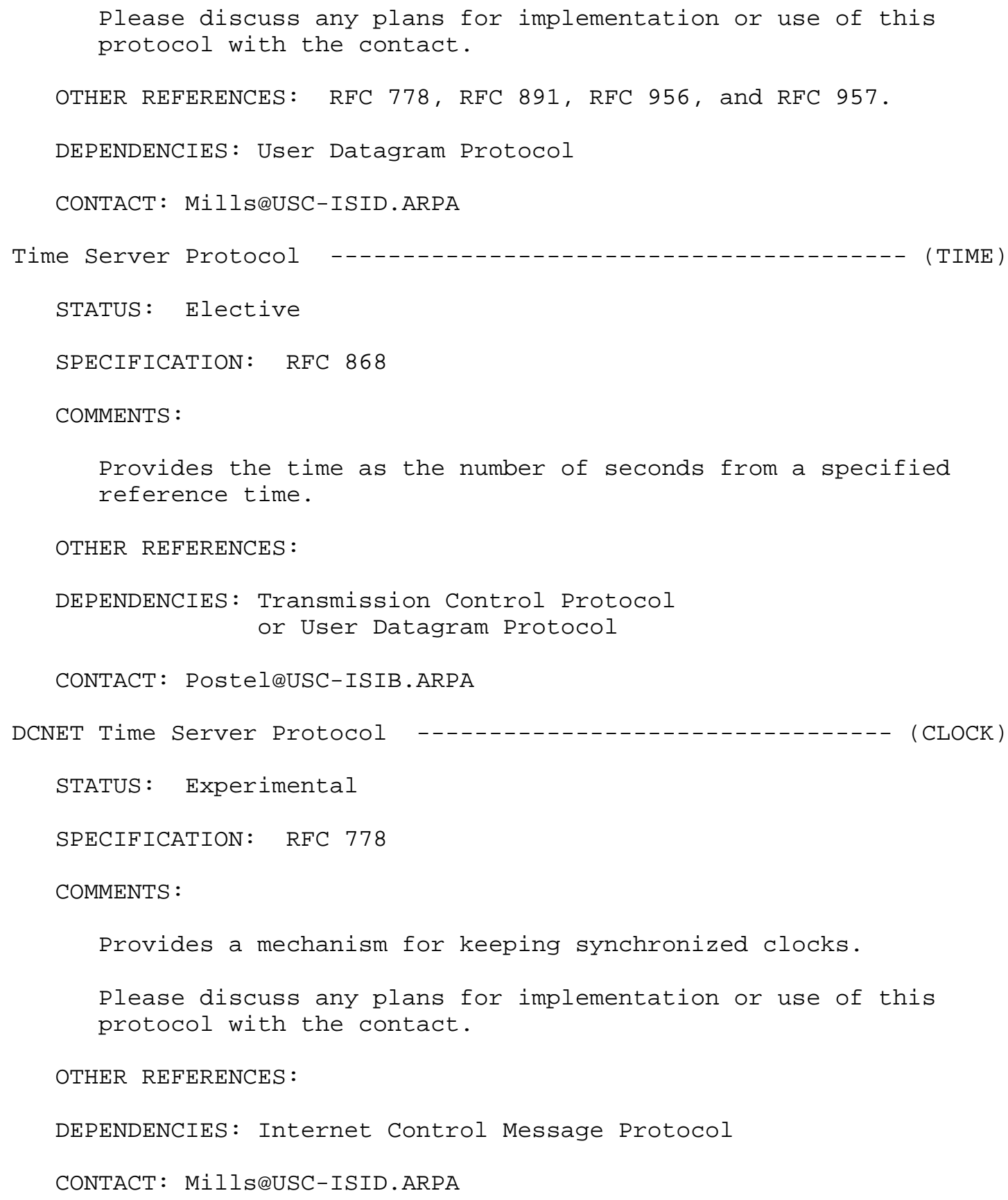




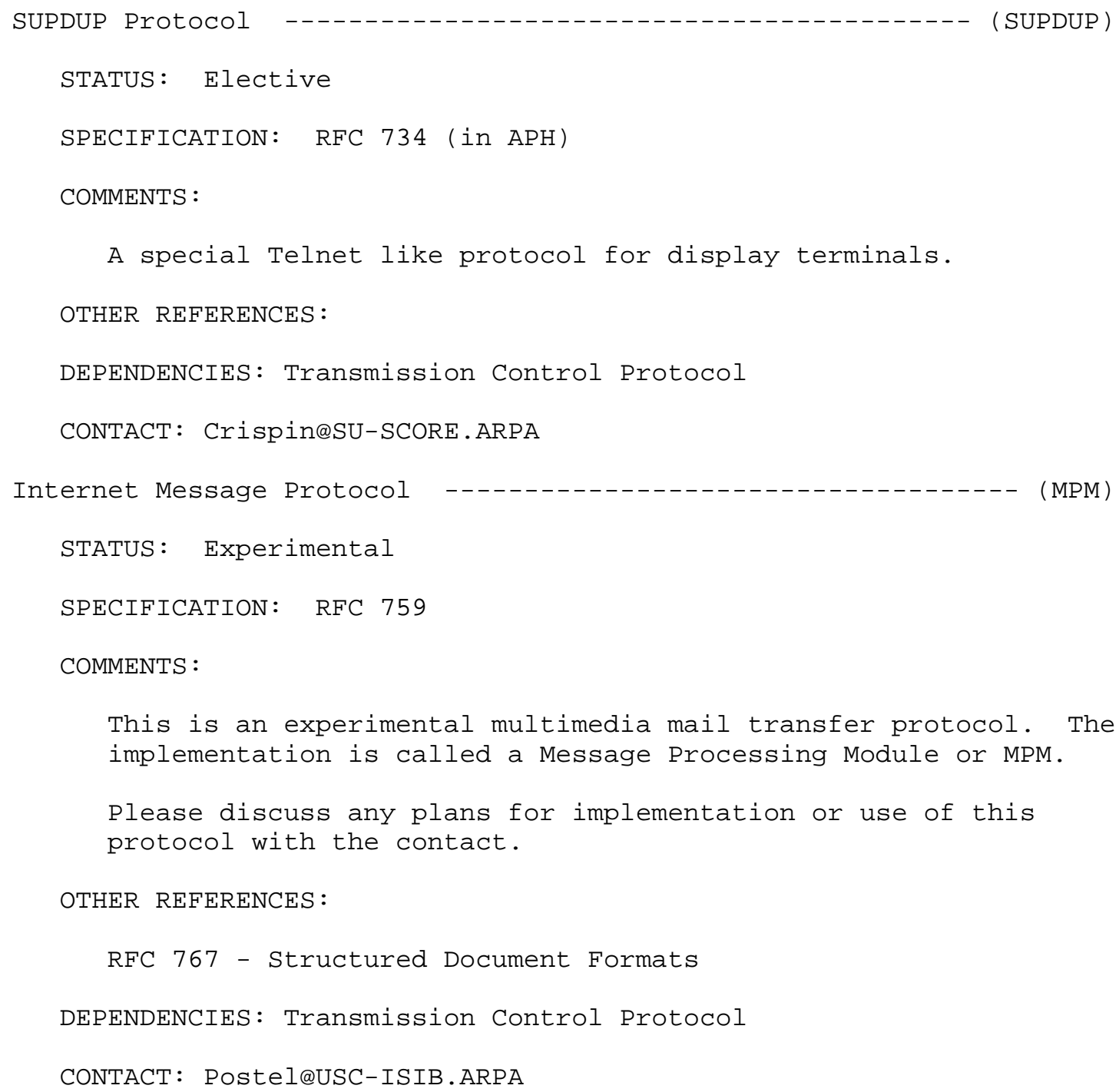




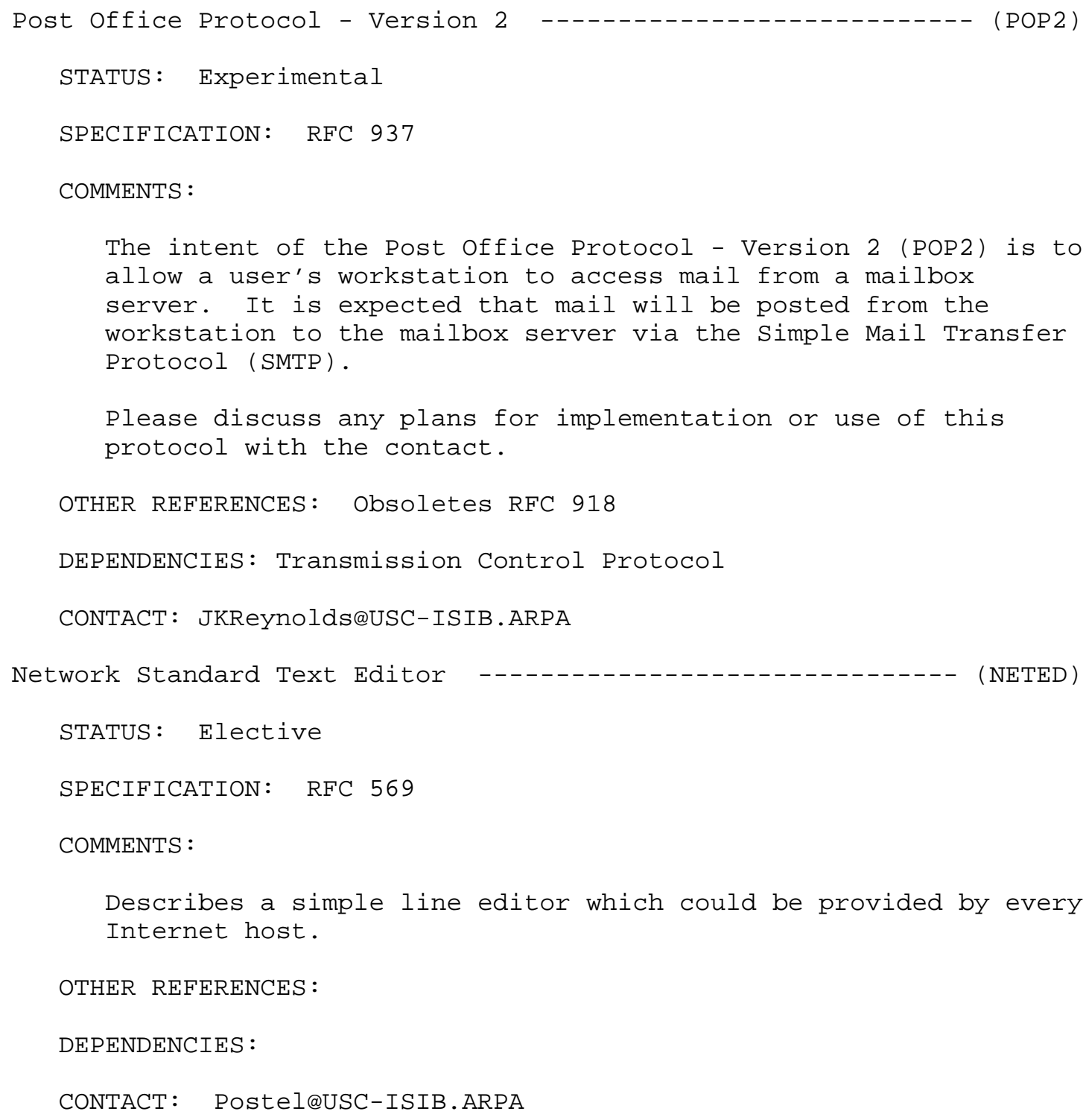




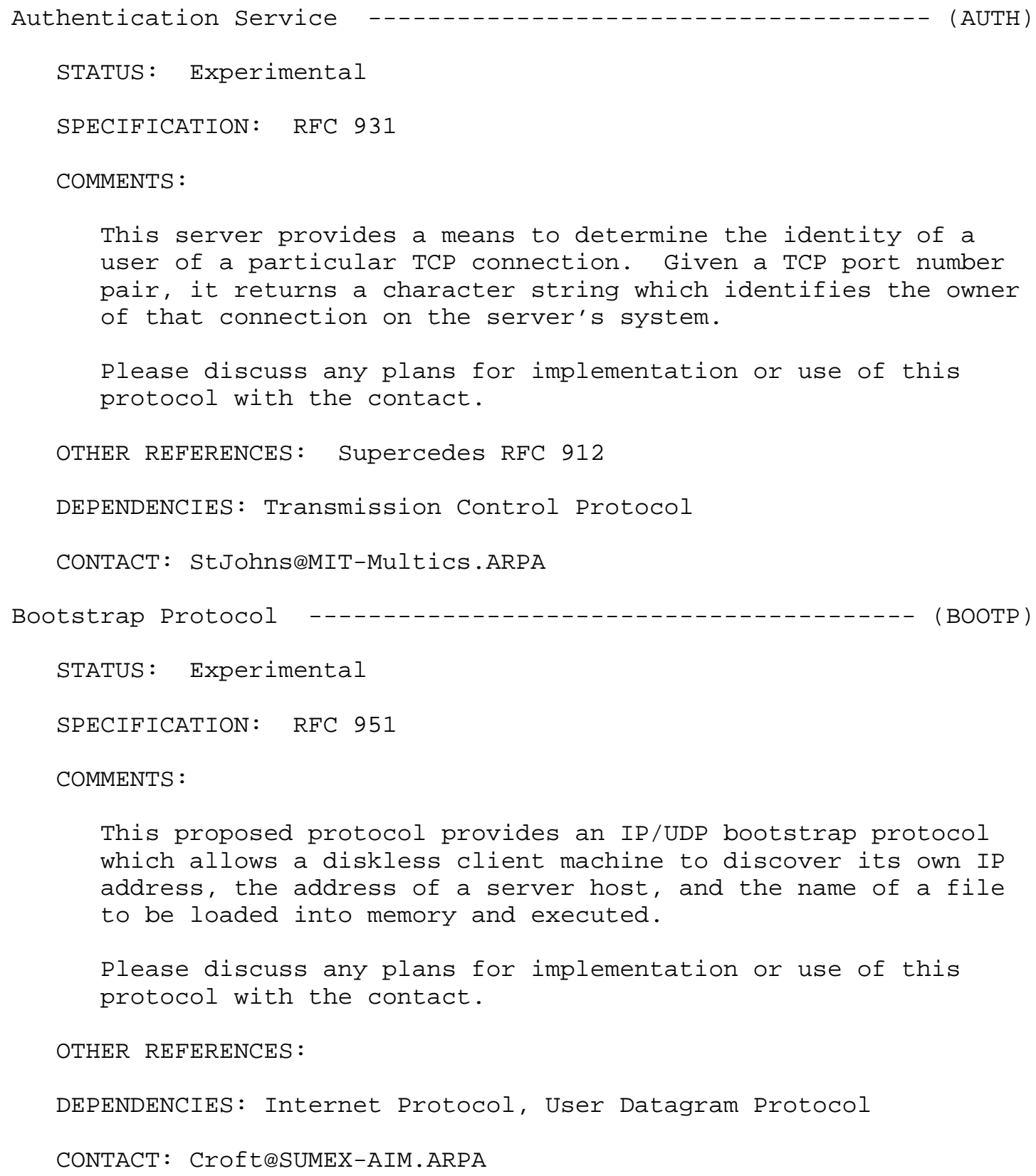


APPENDICES

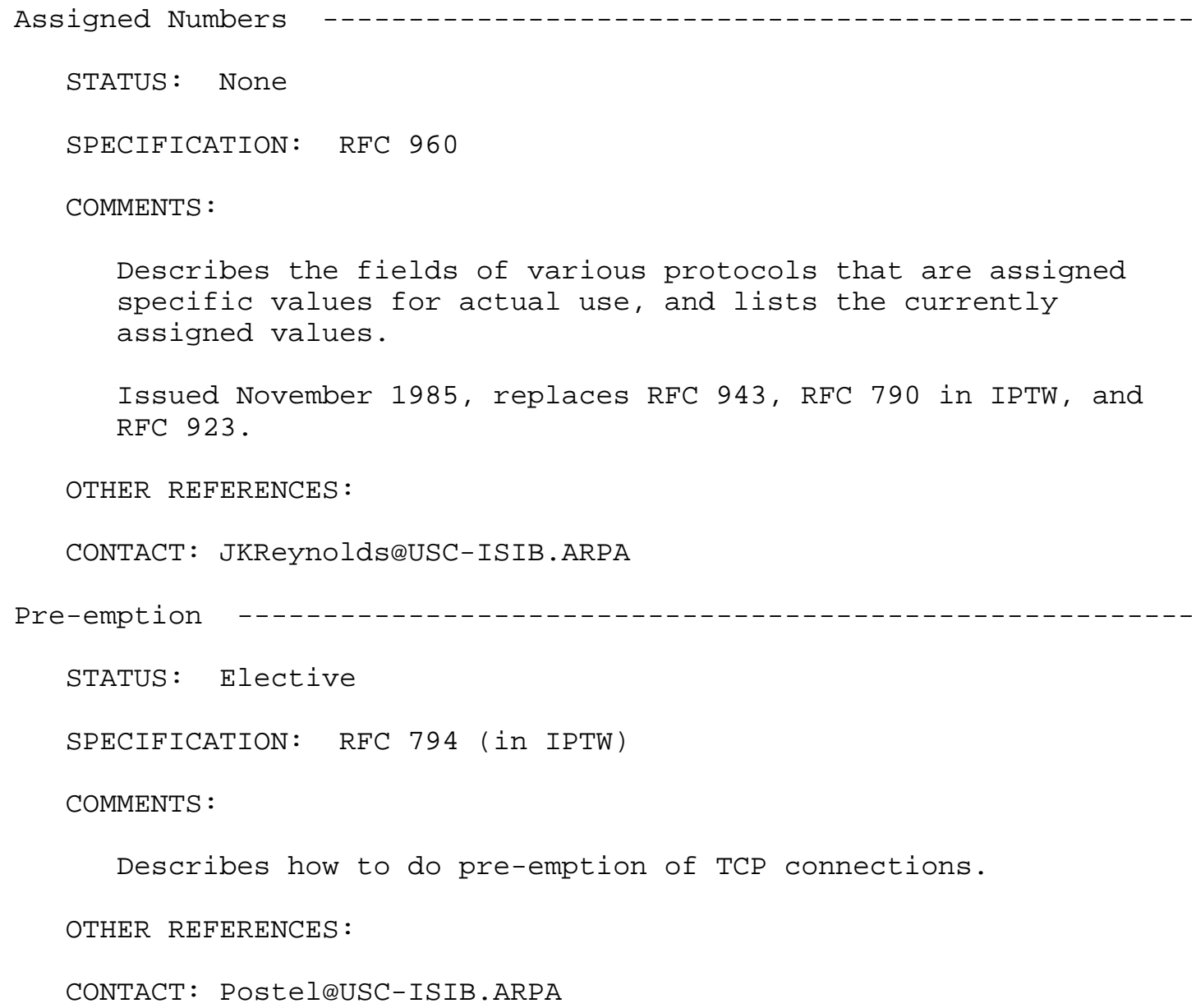




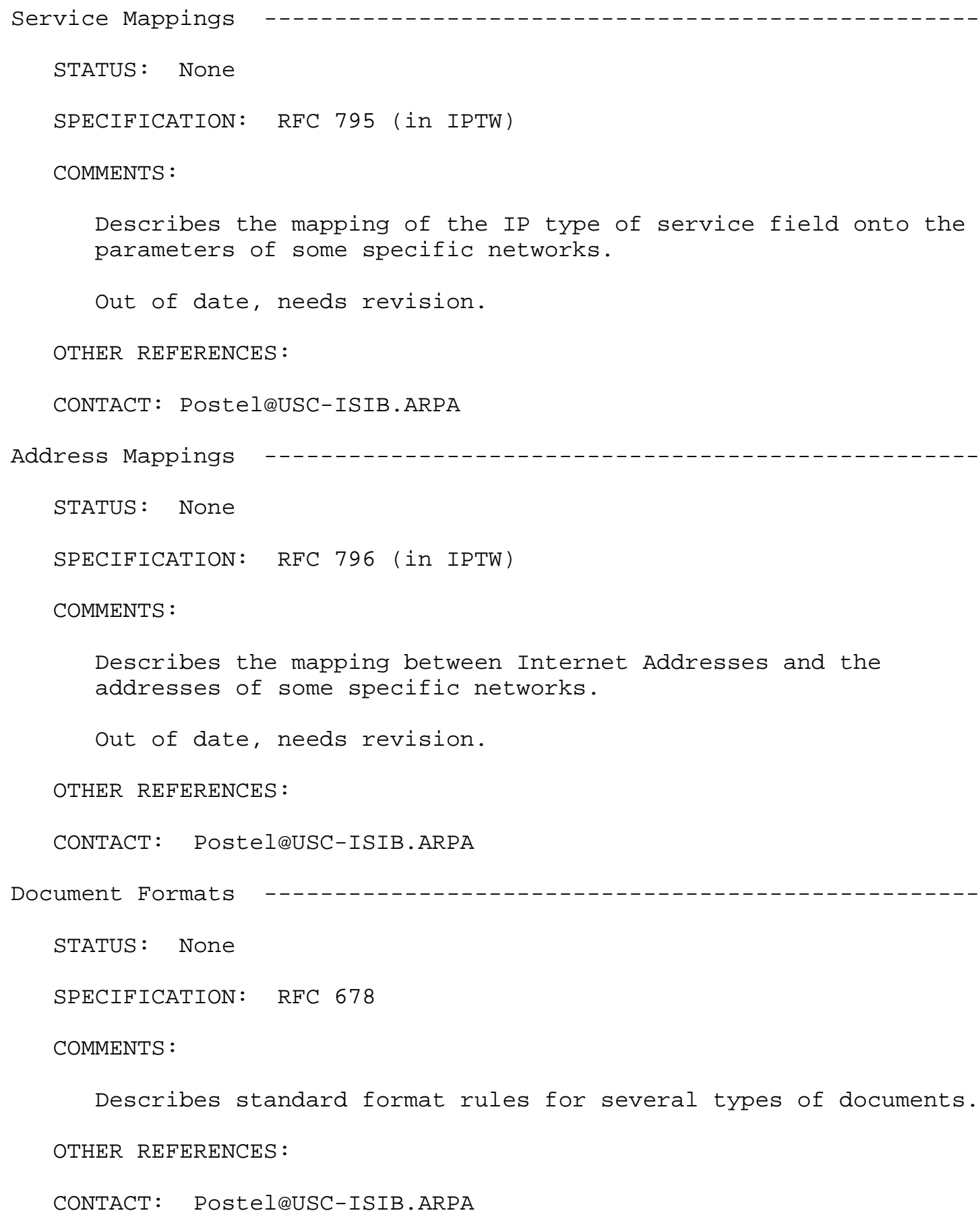




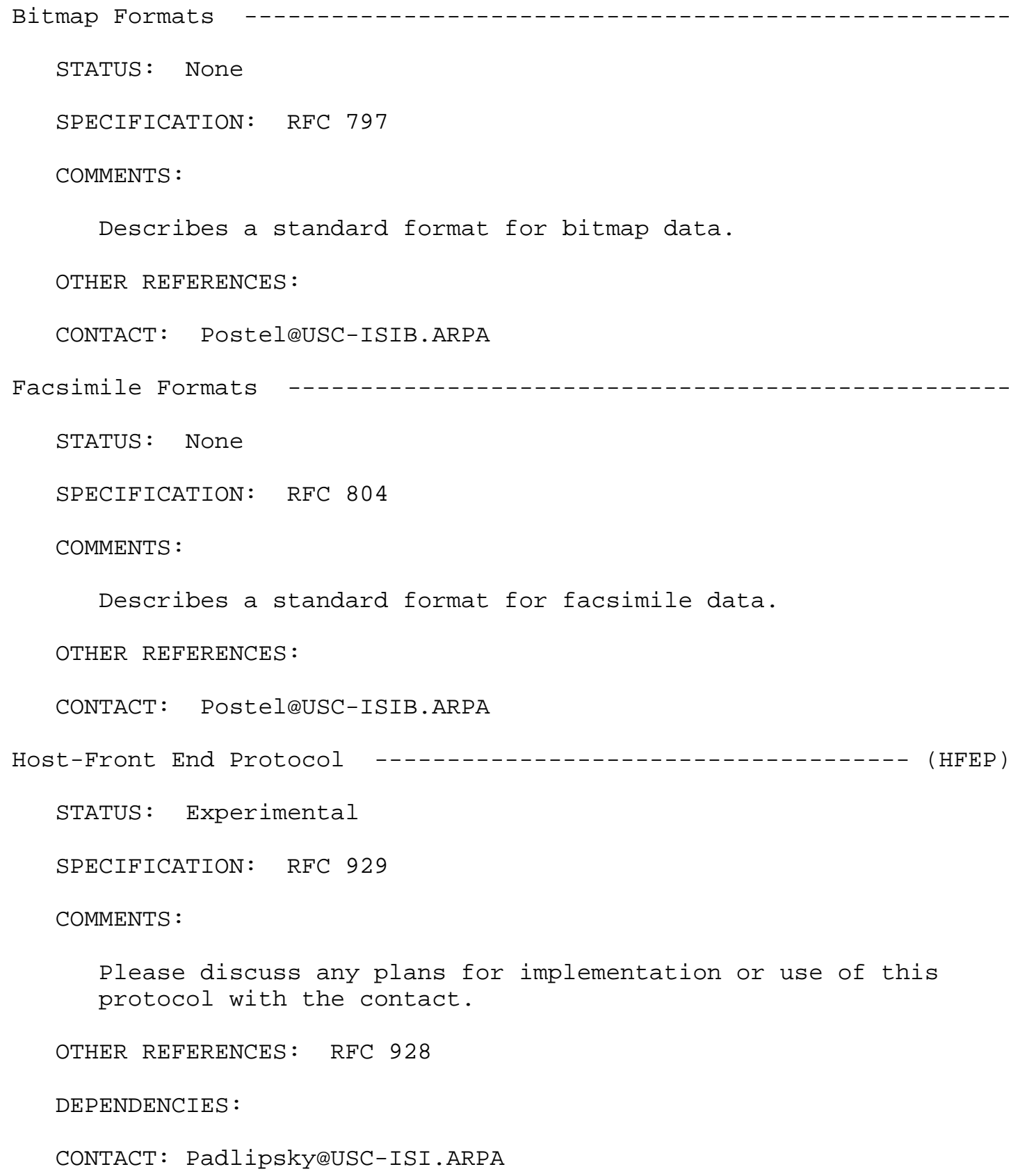




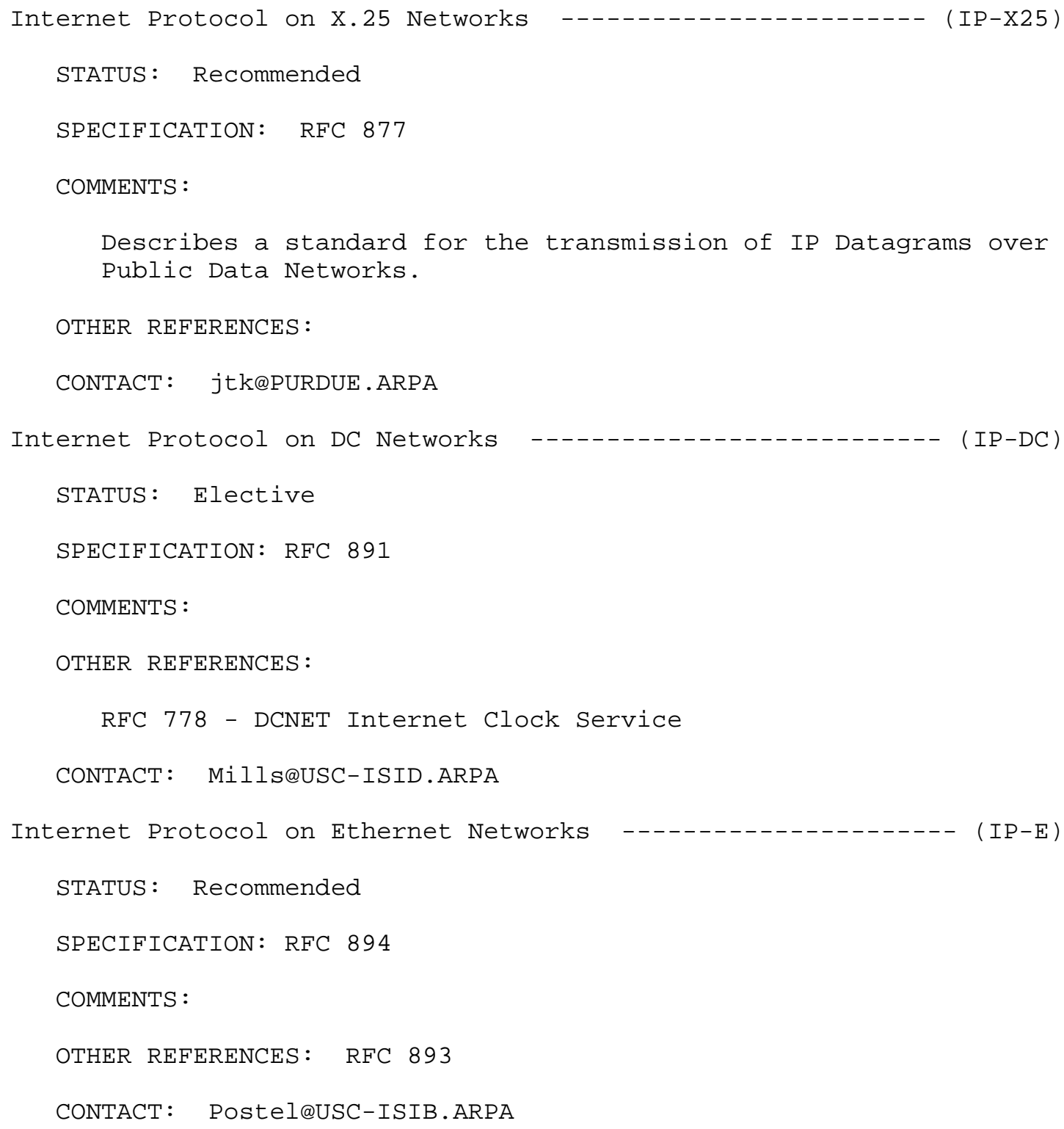




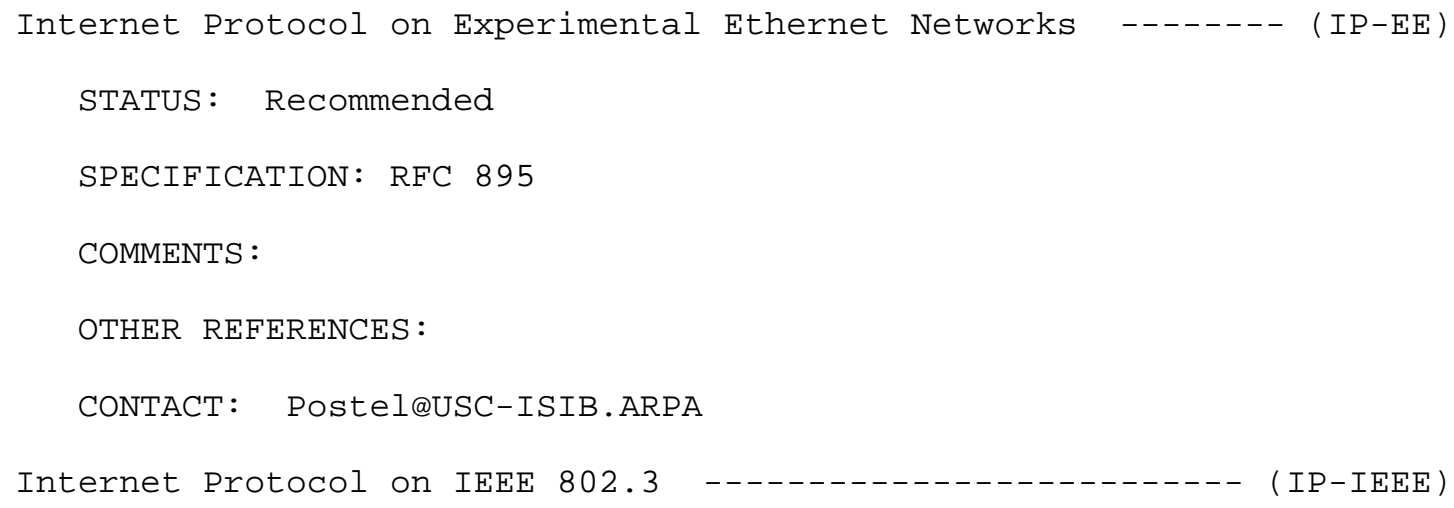




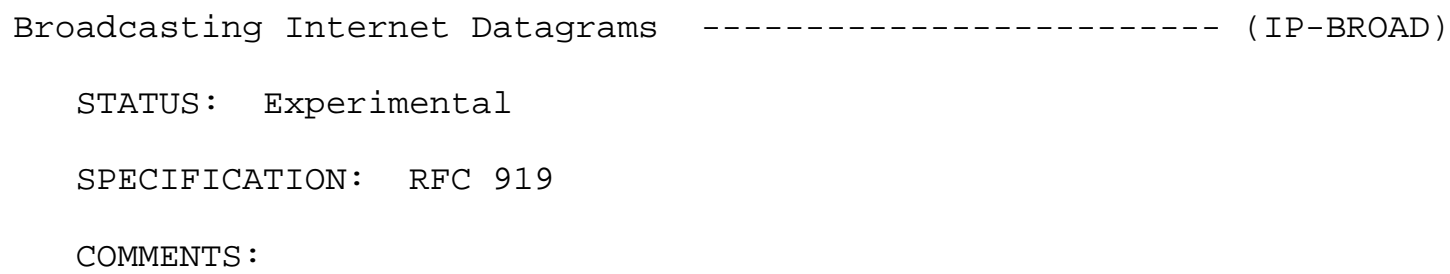

A proposed protocol of simple rules for broadcasting Internet datagrams on local networks that support broadcast, for addressing broadcasts, and for how gateways should handle them.

Please discuss any plans for implementation or use of this protocol with the contact.

OTHER REFERENCES: RFC 922

DEPENDENCIES :

CONTACT: MogulQSU-SCORE.ARPA

Address Resolution Protocol (ARP)

STATUS: Recommended

SPECIFICATION: RFC 826

COMMENTS :

This is a procedure for finding the network hardware address corresponding to an Internet Address.

OTHER REFERENCES:

CONTACT: Postel@USC-ISIB.ARPA

A Reverse Address Resolution Protocol ----------------------- (RARP)

STATUS: Elective

SPECIFICATION: RFC 903

\section{COMMENTS :}

This is a procedure for workstations to dynamically find their protocol address (e.g., their Internet Address), when they only only know their hardware address (e.g., their attached physical network address). 
OTHER REFERENCES:

CONTACT: MoguleSU-SCORE.ARPA

Multi-LAN Address Resolution Protocol

(MARP)

STATUS: Experimental

SPECIFICATION: RFC 925

COMMENTS :

Discussion of the various problems and potential solutions of

"transparent subnets" in a multi-LAN environment.

Please discuss any plans for implementation or use of this protocol with the contact.

OTHER REFERENCES: RFC 917, RFC 826

DEPENDENCIES :

CONTACT: Postel@USC-ISIB.ARPA

Broadcasting Internet Datagrams with Subnets --------- (IP-SUB-BROAD)

STATUS: Experimental

SPECIFICATION: RFC 922

COMMENTS :

A proposed protocol of simple rules for broadcasting Internet datagrams on local networks that support broadcast, for addressing broadcasts, and for how gateways should handle them.

Please discuss any plans for implementation or use of this protocol with the contact.

OTHER REFERENCES:

DEPENDENCIES :

CONTACT: Mogul@SU-SCORE.ARPA 


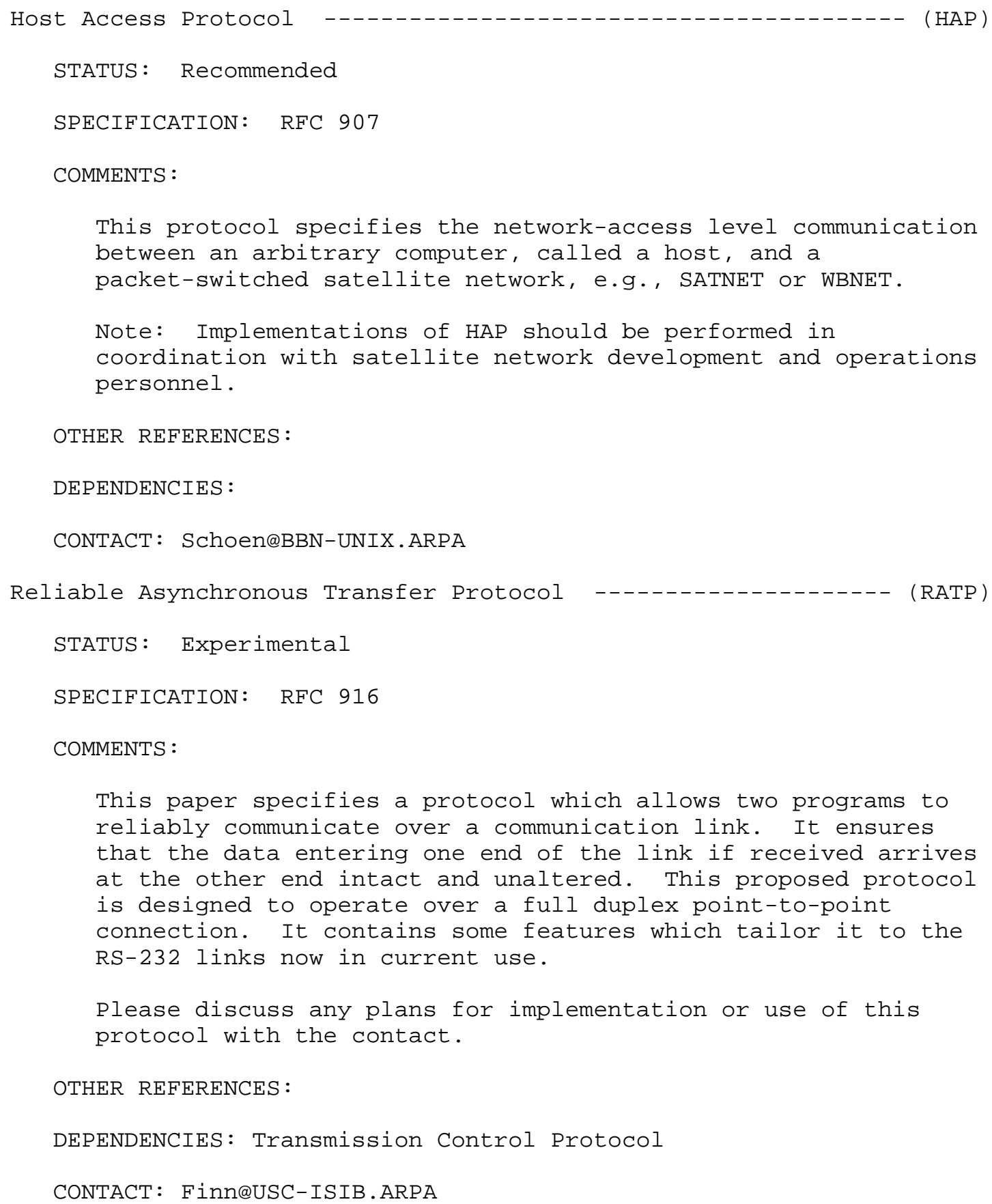




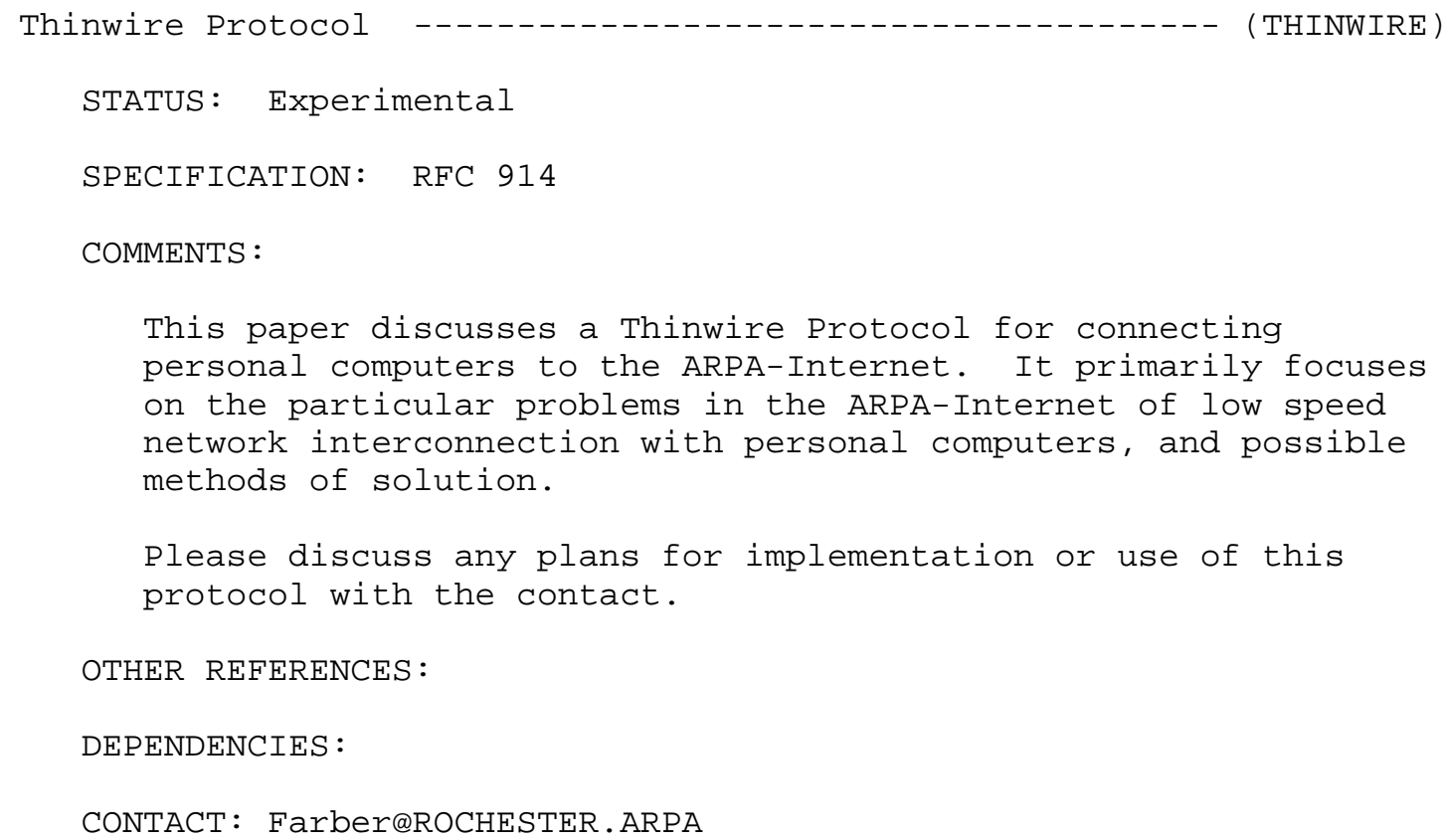

